\title{
Research
}

\section{Risk of suicide during treatment with venlafaxine, citalopram, fluoxetine, and dothiepin: retrospective cohort study}

\author{
Annalisa Rubino, Neil Roskell, Pat Tennis, Daniel Mines, Scott Weich, Elizabeth Andrews
}

\begin{abstract}
Objective To compare the risk of suicide in adults using the antidepressant venlafaxine compared with citalopram, fluoxetine, and dothiepin.

Design Retrospective cohort study.

Setting UK General Practice Research Database.

Participants 219088 patients, aged 18-89 years, who were prescribed venlafaxine, citalopram, fluoxetine, or dothiepin from 1995 to 2005.

Main outcome measures Completed suicide and attempted suicide.

Results Venlafaxine users had a higher burden of risk factors for suicide, including previous suicide attempts and proxies for severe depression or depression that was difficult to treat. In the analysis for completed suicides, unadjusted and adjusted hazard ratios for venlafaxine compared with citalopram were 2.44 (95\% confidence interval 1.12 to 5.31 ) and 1.70 (0.76 to 3.80), for venlafaxine compared with fluoxetine were 2.85 (1.37 to 5.94 ) and 1.63 (0.74 to 3.59), and for venlafaxine compared with dothiepin were 2.54 (1.07 to 6.02 ) and 1.31 (0.53 to 3.25). Compared with other study drugs, venlafaxine was also associated with an increased risk of attempted suicide, but adjustment for measured confounders substantially reduced the hazard ratios.

Conclusions Venlafaxine use was consistently associated with higher risk of suicide compared with citalopram, fluoxetine, and dothiepin. Venlafaxine users had a higher burden of suicide risk factors, however, and adjustment for measured confounders substantially reduced the excess risks. Since the secondary data used in this analysis allowed only indirect and partial measurements of potential confounders, it is possible that residual confounding explains much, if not all, of the observed excess risk.
\end{abstract}

\section{Introduction}

In late 2004 drug regulatory agencies in the United States and Europe warned that adults being treated with antidepressants should be monitored closely for worsening of depression and for increased suicidal thinking or behaviour, particularly at the start of treatment or when changing doses. ${ }^{12}$ This action was largely in response to meta-analyses of randomised controlled trials in patients younger than 19, which found that selective serotonin reuptake inhibitors and other newer antidepressants may increase the risk of suicidal thinking and self harm. ${ }^{3}{ }^{4}$ Three meta-analyses of clinical trials in adults, however, found no increased risk of suicide associated with antidepressants compared with placebo..$^{5-7}$ Observational studies have not found any substantial and consistent differences in suicide risk across commonly prescribed selective serotonin reuptake inhibitors and tricyclic antidepressants. ${ }^{8-13}$ No observational studies have, however, quantified a potential association between treatment with venlafaxine and risk of suicide.

Venlafaxine, a serotonin and noradrenaline reuptake inhibitor, is an antidepressant indicated for the treatment of depression and anxiety. In clinical practice it has often been prescribed for patients unresponsive to selective serotonin reuptake inhibitors or tricyclic antidepressants. ${ }^{14}{ }^{15}$ A recent observational study showed that patients treated with venlafaxine had a higher prevalence of risk factors for suicide, including previous suicide attempt, admission to hospital for depression, and diagnoses of schizophrenia and bipolar disorder than patients prescribed selective serotonin reuptake inhibitors. ${ }^{16}$ We assessed whether the risk of completed and attempted suicide in patients prescribed venlafaxine differs from that in patients prescribed other antidepressants.

We carried out a retrospective cohort study in the general practice research database, which collects electronic medical records within UK primary care. ${ }^{17}{ }^{18}$ To minimise confounding by severity of disease, we selected the selective serotonin reuptake inhibitor citalopram as a comparator antidepressant. As citalopram and venlafaxine were introduced in the same year, we assumed that doctors would preferentially prescribe both agents to patients who were unresponsive to previously available therapies $^{19}$ and presumably had similar background risks of suicide. We also selected fluoxetine and dothiepin because they are the most commonly prescribed drugs within their respective classes.

\section{Methods}

We selected patients on the basis of an incident prescription (that is, first ever prescription in the patient's medical record) for venlafaxine, citalopram, fluoxetine, or dothiepin during the study period 1995 to 2005 . After we applied the quality control criteria for the general practice research database, we restricted the study population to patients aged 18 to 89 years at the time of incident prescription for any study drug, and with a record of depression or anxiety. To characterise medical history, we selected patients with one or more years of follow-up within the database before the incident prescription.

Patients were followed from their incident prescription date until the earliest of completed suicide or first attempted suicide, the end of the study period, or the end of the patient's record. We

Operational definitions and coding for suicides are on bmj.com 
censored follow-up time during periods of no use of any study drug.

\section{Outcome measures}

We defined two end points: completed suicide and the first attempted suicide during the study period, including completed suicides.

Completed suicide was defined by any coding for death associated with mention of suicide in free text entries or by a code for suicide in the medical record accompanied by a statement of death in the administrative record (30 days either way). For the completed suicide analysis we included patients with records of attempted suicide during the study period.

Attempted suicides were identified by a code for suicide attempts. We excluded records that at the review of free text notes did not seem to represent attempted suicide-for example, unintentional overdose or self harm without suicidal intent (see bmj.com).

\section{Exposure to study drugs}

We assumed that exposure to any study drug began on the day after the prescription date and extended to 14 days after the imputed end of the prescription, based on number of pills supplied and dosing instructions. If there was no gap between the imputed end of a first prescription plus 14 days and the date of the subsequent prescription for the same drug, then we concatenated the two periods to represent a continuous episode of treatment. We concatenated subsequent prescriptions similarly. Each participant could experience multiple episodes of treatment for one or more study drugs.

When prescription records indicated concomitant use of multiple antidepressants, including non-study antidepressants, we assumed there was a switch in therapy. When switching therapy participants could have been exposed to more than one antidepressant for a short period, and we accounted for this "overlap with other antidepressant" in the stratified and multivariable analyses. We also examined the effect of allocating usage time for only seven days after the imputed end of a prescription.

\section{Analysis covariates}

To account for potential confounders we identified known risk factors for suicide, including the severity of underlying disease. The confounders we considered were age, sex, diagnosis for study inclusion (depression or anxiety, or both), suicide attempts, major life events, lifestyle factors, family history of psychiatric morbidity, psychotropic comedications, and psychiatric comorbidities. Age was categorised into the groups 18-29, 30-59, and 60 or more years. We also evaluated chronic and disabling nonpsychiatric morbidities that are known to be associated with onset or worsening of depression. We estimated severity of depression and depression that was resistant to treatment using proxies such as admission to hospital and referrals to specialist mental health services, history of antidepressant treatment, antidepressant multitherapy, and number of other previous antidepressants. We also used an initial prescription of 14 days or less as a proxy for clinician perceived risk of suicide. Because the first 30 days of treatment with antidepressants have been associated with a higher risk of suicide, ${ }^{10}$ we coded this period separately.

At the start of each treatment episode we reassessed confounding factors that could change throughout follow-up (for example, psychotropic therapy). We derived confounders for any time and for one month, one year, and ever before an episode of treatment, as appropriate.

\section{Statistical analysis}

For each drug group we calculated the incidence rate (95\% confidence intervals) for completed suicide and first attempted suicide by dividing the number of outcomes by the total person time of use of each drug (person years at risk). We evaluated the potential confounding effect of each covariate by comparing unadjusted and adjusted incidence rate ratios using MantelHaenszel methods.

For each outcome we built a time dependent Cox hazards regression model. Follow-up time was linked to calendar time. Time zero was set at 1 January 1995. Patients could contribute usage time to more than one treatment. To avoid saturation of the statistical model in the completed suicide analysis we limited the analysis covariates to age, sex, age-sex interaction, overlap with other antidepressants, and the 10 confounders associated with the largest changes of the adjusted incidence rate ratio of venlafaxine with each comparator. This resulted in 24 analysis covariates because we introduced those confounders identified in more than one paired comparison (for example, venlafaxine versus citalopram, venlafaxine versus fluoxetine, and venlafaxine versus dothiepin) only once in the model. The larger number of outcomes in the attempted suicide analysis allowed us to include in the model all the variables that modified the adjusted incidence rate ratios. We estimated hazard ratios $(95 \%$ confidence intervals) for each treatment comparison and for each potential confounder in the model. All analyses were carried out using SAS for UNIX software (version 9.1).

\section{Results}

Overall, 219088 patients aged 18-89 years who were prescribed venlafaxine, citalopram, fluoxetine, or dothiepin from 1995 to 2005 were identified from the general practice research database. The distribution of the population characteristics across drug groups and analysis covariates used in the completed and the attempted suicide analyses were similar. Table 1 provides data from the completed suicide analysis only.

Distributions of age and sex were consistent across drug groups (table 1). Most patients $(90.5 \%, \mathrm{n}=198231)$ had a diagnosis of depression as opposed to anxiety. About 25\% of patients had both diagnoses, and this proportion was higher among patients treated with venlafaxine $(35.4 \%, \mathrm{n}=7725)$ than among those treated with fluoxetine $(22.0 \% \quad \mathrm{n}=20893)$, citalopram $(27.3 \%, \mathrm{n}=16073)$, or dothiepin $(23.9 \%, \mathrm{n}=10387)$. Patients prescribed venlafaxine also showed signs of more severe or difficult to treat depression. For instance, history of other antidepressant therapy, history of antidepressant multitherapy, and history of treatment with three or more antidepressants were more common among patients treated with venlafaxine (table 1). Furthermore, proxies of depression severity, such as admission to hospital for psychiatric disorders and referral to specialist mental health care, were more common among those prescribed venlafaxine than those prescribed comparator drugs (table 1). Previous attempted suicide was twice as common among venlafaxine users than among citalopram or fluoxetine users. Other suicide risk factors, including psychotropic therapy and family history of psychiatric disorders, were also more common among venlafaxine users (table 1). Distribution of chronic or incapacitating morbidities known to be associated with depression did not differ across drug groups. Similarly, bereavement or marital problems were equally distributed across groups (table 1).

\section{Incidence rate and hazard ratio}

The completed suicide analysis encompassed 54 events over 173452 person years for use of any study drug, and the first 
Table 1 Frequency distribution of population characteristics by antidepressant use in completed suicide analysis. Values are percentages (numbers) unless stated otherwise

\begin{tabular}{|c|c|c|c|c|}
\hline Characteristic & Venlafaxine & Citalopram & Fluoxetine & Dothiepin \\
\hline No of participants & 37857 & 75749 & 108934 & 54035 \\
\hline Mean (SD) age (years) & $46.2(16.4)$ & $47.1(18.0)$ & $43.9(16.7)$ & $48.6(7.3)$ \\
\hline Men & $\begin{array}{c}33.5(12 \\
671)\end{array}$ & $\begin{array}{c}30.5(23 \\
108)\end{array}$ & $\begin{array}{l}30.6(33 \\
322)\end{array}$ & $\begin{array}{l}30.0(16 \\
212)\end{array}$ \\
\hline No of treatment episodes & 89296 & 160189 & 283865 & 125123 \\
\hline First prescription $\leq 14$ days & $9.9(8872)$ & $7.3(11622)$ & $\begin{array}{c}19.7(55 \\
960)\end{array}$ & $\begin{array}{c}10.2(12 \\
751)\end{array}$ \\
\hline $\begin{array}{l}\text { Overlap with other } \\
\text { antidepressants }\end{array}$ & $\begin{array}{l}22.4(19 \\
997)\end{array}$ & $\begin{array}{c}11.6(18 \\
554)\end{array}$ & 8.7 (24 705) & $\begin{array}{c}13.4(16 \\
755)\end{array}$ \\
\hline $\begin{array}{l}\text { Exposure during first } 30 \text { days } \\
\text { of treatment episode }\end{array}$ & $\begin{array}{c}53.8(48 \\
036)\end{array}$ & $\begin{array}{l}59.9(96 \\
019)\end{array}$ & $\begin{array}{l}54.8(155 \\
571)\end{array}$ & $\begin{array}{c}59.5(74 \\
408)\end{array}$ \\
\hline \multicolumn{5}{|l|}{$\begin{array}{l}\text { Drug history before treatment } \\
\text { episode: }\end{array}$} \\
\hline Same antidepressant & $\begin{array}{l}61.6(55 \\
008)\end{array}$ & $\begin{array}{c}54.3(87 \\
000)\end{array}$ & $\begin{array}{c}63.2(179 \\
492)\end{array}$ & $\begin{array}{c}60.4(75 \\
535)\end{array}$ \\
\hline Other antidepressants & $\begin{array}{l}90.6(80 \\
871)\end{array}$ & $\begin{array}{l}68.7(109 \\
972)\end{array}$ & $\begin{array}{l}59.9(170 \\
077) \\
\end{array}$ & $\begin{array}{c}62.6(78 \\
283) \\
\end{array}$ \\
\hline $\begin{array}{l}\text { Other antidepressants in } \\
\text { previous year }\end{array}$ & $\begin{array}{c}55.9(49 \\
960)\end{array}$ & $\begin{array}{c}32.5(52 \\
056)\end{array}$ & $\begin{array}{c}25.8(73 \\
278)\end{array}$ & $\begin{array}{c}32.3(40 \\
428)\end{array}$ \\
\hline $\begin{array}{l}\text { History of antidepressant } \\
\text { multitherapy }\end{array}$ & $\begin{array}{c}13.4(11 \\
933)\end{array}$ & $7.2(11588)$ & 5.8 (16 599) & $7.4(9207)$ \\
\hline \multicolumn{5}{|l|}{$\begin{array}{l}\text { No of other previous } \\
\text { antidepressants: }\end{array}$} \\
\hline 0 & $9.4(8425)$ & $\begin{array}{l}31.3(50 \\
217)\end{array}$ & $\begin{array}{l}40.1(113 \\
788)\end{array}$ & $\begin{array}{l}37.4(46 \\
840)\end{array}$ \\
\hline$\geq 3$ & $\begin{array}{c}40.8(36 \\
417)\end{array}$ & $\begin{array}{c}22.9(36 \\
610)\end{array}$ & $\begin{array}{c}14.7(41 \\
753)\end{array}$ & $\begin{array}{c}17.3(21 \\
591)\end{array}$ \\
\hline $\begin{array}{l}\text { Any psychotropic therapy }{ }^{*} \text { in } \\
60 \text { days before treatment } \\
\text { episode }\end{array}$ & $\begin{array}{c}25.8(23 \\
014)\end{array}$ & $\begin{array}{c}18.2(29 \\
162)\end{array}$ & $\begin{array}{c}13.9(39 \\
566)\end{array}$ & $\begin{array}{c}18.5(23 \\
162)\end{array}$ \\
\hline $\begin{array}{l}\text { Suicidal behaviour in year } \\
\text { before treatment episode }\end{array}$ & $1.9(1737)$ & $0.9(1423)$ & 0.8 (2213) & $0.4(549)$ \\
\hline $\begin{array}{l}\text { Admission to hospital for } \\
\text { psychiatric disorders in } \\
\text { month before treatment } \\
\text { episode }\end{array}$ & $1.2(1098)$ & $0.9(1403)$ & $0.6(1825)$ & $0.6(726)$ \\
\hline $\begin{array}{l}\text { Psychiatric referral in year } \\
\text { before treatment episode }\end{array}$ & $3.4(3002)$ & $1.7(2756)$ & 1.0 (2979) & $0.7(913)$ \\
\hline $\begin{array}{l}\text { Any psychiatric morbidity }{ }^{\text {in }} \\
\text { year before treatment } \\
\text { episode }\end{array}$ & $\begin{array}{l}76.8(68 \\
609)\end{array}$ & $\begin{array}{l}78.4(125 \\
561)\end{array}$ & $\begin{array}{l}77.3(219 \\
540)\end{array}$ & $\begin{array}{c}69.8(87 \\
306)\end{array}$ \\
\hline Non-psychiatric morbidity & $\begin{array}{c}11.2(10 \\
036)\end{array}$ & $\begin{array}{l}11.9(18 \\
988)\end{array}$ & $\begin{array}{c}10.3(29 \\
333)\end{array}$ & $\begin{array}{l}12.2(15 \\
279)\end{array}$ \\
\hline Major life events & $2.8(2469)$ & $2.9(4693)$ & $2.9(8303)$ & $3.6(4493)$ \\
\hline Lifestyle factors & $8.5(7581)$ & $7.4(11830)$ & $5.1(14618)$ & $4.5(5576)$ \\
\hline $\begin{array}{l}\text { Family history of psychiatric } \\
\text { morbidity }\end{array}$ & $2.1(1846)$ & $1.5(2344)$ & 1.1 (2999) & $1.0(1205)$ \\
\hline
\end{tabular}

*Mood stabilisers, including carbamazepine, clonazepam, gabapentin, lamotrigine, lithium, topiramate, valproic acid, antipsychotics, and benzodiazepines.

†Depression, including dysthymia and chronic fatigue syndrome; somatoform disorders (for example, somatisation disorder and hypochondriasis); eating disorders (anorexia and bulimia nervosa); anxiety disorders, including phobias (social phobia, agoraphobia, simple phobias), obsessive-compulsive disorder, panic disorder, and post-traumatic stress disorder; mixed anxiety depressive disorder; bipolar affective disorder; schizophrenia; substance abuse disorder and alcohol abuse syndrome; dementia; and personality disorders, including schizoid, borderline, and antisocial behaviour.

‡Cancer, Parkinson’s disease, multiple sclerosis, diabetes, cirrhosis, myocardial infarction, stroke, renal failure, respiratory diseases, and arthritis.

attempted suicide analysis encompassed 3060 events over 169735 person years at risk. The incidence rate of both completed and first attempted suicide was higher for venlafaxine treatment than for each comparator treatment (table 2).

Mantel-Haenszel adjusted incidence rate ratios were calculated for both the completed and the attempted suicide analyses (data not shown). In both analyses, adjustment for the higher risk of suicide during the first 30 days of treatment consistently increased the incidence rate ratio in each comparison. For most confounders, however, adjustment was associated with a reduction in the incidence rate ratio. History of antidepressant
Table 2 Unadjusted incidence rate (95\% confidence interval) of completed and first attempted suicides in adults according to antidepressant

\begin{tabular}{|c|c|c|c|c|}
\hline Event and antidepressant & $\begin{array}{c}\text { No of } \\
\text { patients }\end{array}$ & $\begin{array}{c}\text { Person years } \\
\text { at risk }\end{array}$ & $\begin{array}{l}\text { No of } \\
\text { events }\end{array}$ & $\begin{array}{c}\text { Incidence rate } \\
(95 \% \mathrm{CI}) \text { per } 1000 \\
\text { person years }\end{array}$ \\
\hline \multicolumn{5}{|l|}{ Completed suicide: } \\
\hline Venlafaxine & 37857 & 28087 & 18 & 0.64 (0.40 to 1.02$)$ \\
\hline Citalopram & 75749 & 45639 & 12 & $0.26(0.15$ to 0.46$)$ \\
\hline Fluoxetine & 108934 & 66636 & 15 & 0.23 (0.14 to 0.37$)$ \\
\hline Dothiepin & 54035 & 33090 & 9 & 0.27 (0.14 to 0.52$)$ \\
\hline \multicolumn{5}{|l|}{ First attempted suicide: } \\
\hline Venlafaxine & 37132 & 26854 & 715 & 26.6 (24.7 to 28.7) \\
\hline Citalopram & 75103 & 44788 & 781 & 17.4 (16.3 to 18.7$)$ \\
\hline Fluoxetine & 108474 & 65416 & 1138 & 17.4 (16.4 to 18.4$)$ \\
\hline Dothiepin & 53818 & 32677 & 426 & 13.0 (11.9 to 14.3$)$ \\
\hline
\end{tabular}

*Patients could contribute person years at risk to more than one antidepressant.

therapy, including antidepressant multitherapy and psychotropic therapy, and previous suicide attempts had the strongest confounding effect on the association between venlafaxine and completed or attempted suicide.

Unadjusted and adjusted hazard ratios were calculated for venlafaxine compared with each study drug. The unadjusted risk of completed suicide was more than twice as high during venlafaxine treatment. Adjustment for the measured confounders in the completed suicide models, however, reduced the excess risk by at least $50 \%$ in each paired comparison (table 3). The unadjusted risk of attempted suicide was also higher during venlafaxine treatment compared with citalopram, fluoxetine, and dothiepin treatments. The hazard ratio was substantially reduced after adjustment for measured confounders (table 4).

When the extended time at risk was reduced from 14 to seven days after the imputed end of a prescription, the adjusted hazard ratio of venlafaxine compared with citalopram increased from 1.70 (95\% confidence interval 0.76 to 3.80$)$ to 1.87 (0.81 to 4.29 ) in the completed suicide analysis and from 1.20 (1.07 to 1.34 ) to 1.23 (1.10 to 1.37 ) in the attempted suicide analysis, but such an increase was inconsistent across comparisons (table 5).

\section{Discussion}

The antidepressant venlafaxine was associated with a higher risk of suicide compared with citalopram, fluoxetine, and dothiepin. Venlafaxine users had a higher burden of risk factors for suicide, however, and adjustment for measured confounders substantially reduced the excess risks. While these data may reflect a causal association between venlafaxine use and suicide, given the substantial attenuation of this association after adjustment for confounding and the nature of the data, it is possible that residual confounding could explain much or all of the remaining risk.

Venlafaxine use in this study population of adults was associated with markers of severe and difficult to treat depression, with psychiatric comorbidities, and with previous treatment with psychotropic agents such as antipsychotics and mood stabilisers. ${ }^{16}$ Admission to hospital for a psychiatric disorder and specialist care, family history of psychiatric morbidities, and a history of suicide attempts were also more prevalent in venlafaxine users. Furthermore, venlafaxine users were twice as likely to have an overlap prescription for another antidepressant, suggesting more frequent switching of drugs. Patients may switch antidepressant drugs owing to failure to achieve the desired therapeutic effect, suggesting that venlafaxine users had severe or treatment resistant depression. 
Table 3 Cox proportional hazard model to estimate risk of completed suicide after adjustment for measured risk factors and confounders

\begin{tabular}{|c|c|}
\hline Analysis covariates & Hazard ratio* $(95 \% \mathrm{Cl})$ \\
\hline Venlafaxine $v$ citalopram & $\begin{array}{c}1.70 \text { (0.76 to } 3.80) ; 2.44 \text { (1.12 to } \\
5.31) \dagger\end{array}$ \\
\hline Venlafaxine $v$ fluoxetine & $\begin{array}{c}1.63 \text { (0.74 to } 3.59) ; 2.85 \text { (1.37 to } \\
5.94) \dagger\end{array}$ \\
\hline Venlafaxine $v$ dothiepin & $\begin{array}{c}1.31 \text { (0.53 to } 3.25) ; 2.54 \text { (1.07 to } \\
6.02) \dagger\end{array}$ \\
\hline Men $v$ women & $2.15(0.53$ to 8.67$)$ \\
\hline \multicolumn{2}{|l|}{ Age at start of treatment episode: } \\
\hline $30-59$ v 18-29 & $0.56(0.17$ to 1.77$)$ \\
\hline$\geq 60 \vee 18-29$ & $0.33(0.07$ to 1.51$)$ \\
\hline \multicolumn{2}{|l|}{ Sex-age interaction: } \\
\hline Men aged 30-59 & $1.83(0.38$ to 8.80$)$ \\
\hline Men aged $\geq 60$ & $2.31 \quad(0.32$ to 16.47$)$ \\
\hline Overlap with other antidepressants (yes $v$ no) & $0.75(0.15$ to 3.65$)$ \\
\hline First 30 days of treatment episode (yes $v$ no) & 2.85 (1.51 to 5.39$)$ \\
\hline Duration of first prescription ( $\leq 14 v \geq 15$ days) & $1.35(0.55$ to 3.31$)$ \\
\hline \multicolumn{2}{|l|}{ Drug history before treatment episode: } \\
\hline Same antidepressant (yes $v$ no) & 0.51 (0.26 to 0.99) \\
\hline Other antidepressants ever before (yes $v$ no) & $0.56(0.21$ to 1.50$)$ \\
\hline Other antidepressants in year before (yes $v$ no) & 2.21 (0.91 to 5.39$)$ \\
\hline No of other previous antidepressants ( $3 v 1$ or 2 ) & 1.00 (0.48 to 2.09) \\
\hline History of antidepressant multitherapy (yes $v$ no) & $1.40(0.59$ to 3.30$)$ \\
\hline $\begin{array}{l}\text { Suicidal behaviour in year before treatment episode } \\
\text { (yes } v \text { no) }\end{array}$ & 7.51 (2.82 to 19.96$)$ \\
\hline $\begin{array}{l}\text { Admission to hospital for psychiatric disorder in } \\
\text { month before treatment episode (yes } v \text { no) }\end{array}$ & 2.53 (0.74 to 8.68$)$ \\
\hline $\begin{array}{l}\text { Psychiatric referral in year before treatment episode } \\
\text { (yes } v \text { no) }\end{array}$ & 0.99 (0.23 to 4.32) \\
\hline \multicolumn{2}{|l|}{$\begin{array}{l}\text { Psychotropic therapy in } 60 \text { days before treatment } \\
\text { episode: }\end{array}$} \\
\hline Any psychotropics (yes $v$ no) & 1.96 (0.86 to 4.42$)$ \\
\hline Antipsychotics (yes $v$ no) & $2.46(1.05$ to 5.80$)$ \\
\hline Mood stabilisers (yes $v$ no) & $0.71(0.22$ to 2.34$)$ \\
\hline $\begin{array}{l}\text { Any psychiatric morbidity in year before treatment } \\
\text { episode (yes } v \text { no) }\end{array}$ & 0.84 (0.39 to 1.82) \\
\hline \multicolumn{2}{|l|}{ Medical history: } \\
\hline Bipolar disorder (yes $v$ no) & 4.94 (1.30 to 18.84$)$ \\
\hline Depression (yes $v$ no) & $1.15(0.34$ to 3.86$)$ \\
\hline Mixed anxiety and depression (yes $v$ no) & 0.71 (0.33 to 1.50$)$ \\
\hline Substance misuse (yes $v$ no) & $1.30(0.54$ to 3.13$)$ \\
\hline
\end{tabular}

* Measures relative risk of completed suicide adjusted for each analysis covariate after adjustment for all other variables in model, including treatment.

†Unadjusted values.

In our study, suicide rates were consistently higher across study drugs during the first 30 days of a treatment episode, confirming that starting antidepressants is associated with a higher risk of suicide. ${ }^{8}$ The study also confirmed that markers for severity of psychiatric morbidity were associated with an increased risk of suicide and suicide attempt in each drug group.

\section{Confounding}

Pharmacoepidemiological studies are potentially confounded by indication; factors associated with choice of therapy may also be risk factors for the study outcome. Although a randomised clinical trial can eliminate such confounding, this design is not feasible to evaluate such rare outcomes as suicide. The richness of longitudinal records in the UK general practice research database allowed us to adjust for many factors associated with the risk of suicide and with the selection of antidepressant treatment, but it is possible that our adjustment was incomplete. The ability to control for confounding depends on the accurate measurement of potential confounders. Even when the sensitivity and specificity of the confounder measures are $90 \%$, more than $30 \%$ of confounding remains uncontrolled. ${ }^{20}$ Adjustment
Table 4 Cox proportional hazard model to estimate risk of attempted suicide in adults according to antidepressants after adjustment for measured risk factors and confounders

\begin{tabular}{|c|c|}
\hline Analysis covariates & Hazard ratio* $(95 \% \mathrm{CI})$ \\
\hline Venlafaxine $v$ citalopram & $\begin{array}{c}1.20 \text { (1.07 to } 1.34) ; 1.49 \text { (1.34 to } \\
1.66) \dagger\end{array}$ \\
\hline Venlafaxine $v$ fluoxetine & $\begin{array}{c}1.28 \text { (1.15 to } 1.42) ; 1.68 \text { (1.52 to } \\
1.86) \dagger\end{array}$ \\
\hline Venlafaxine $v$ dothiepin & $\begin{array}{c}1.47 \text { (1.29 to } 1.68) ; 2.41(2.11 \text { to } \\
2.74) \dagger\end{array}$ \\
\hline Men $v$ women & $0.98(0.85$ to 1.14$)$ \\
\hline \multicolumn{2}{|l|}{ Age at start of treatment episode: } \\
\hline $30-59 \vee 18-29$ & $0.37(0.33$ to 0.41$)$ \\
\hline$\geq 60$ v 18-29 & $0.12(0.10$ to 0.14$)$ \\
\hline \multicolumn{2}{|l|}{ Sex-age interaction: } \\
\hline Men aged 30-59 & $1.18(0.99$ to 1.41$)$ \\
\hline Men aged $\geq 60$ & 1.42 (1.04 to 1.93$)$ \\
\hline Overlap with other antidepressants (yes $v$ no) & 1.74 (1.45 to 2.08$)$ \\
\hline First 30 days of treatment episode (yes $v$ no) & 2.08 (1.91 to 2.27) \\
\hline Duration of first prescription ( $\leq 14 v \geq 15$ days) & 1.65 (1.46 to 1.86$)$ \\
\hline \multicolumn{2}{|l|}{ Drug history: } \\
\hline Same antidepressant (yes $v$ no) & $0.73(0.67$ to 0.80$)$ \\
\hline $\begin{array}{l}\text { Other antidepressant in year before treatment } \\
\text { episode (yes } v \text { no) }\end{array}$ & $1.17(1.05$ to 1.29$)$ \\
\hline \multicolumn{2}{|l|}{ No of previous other antidepressants: } \\
\hline 1 or $2 \vee 0$ & $1.04(0.93$ to 1.16$)$ \\
\hline $3 \vee 0$ & $1.14(1.00$ to 1.31$)$ \\
\hline History of antidepressant multitherapy (yes $v$ no) & 1.01 (0.88 to 1.16$)$ \\
\hline $\begin{array}{l}\text { Admission to hospital for psychiatric disorders in } \\
\text { month before treatment episode (yes } v \text { no) }\end{array}$ & 3.06 (2.48 to 3.77$)$ \\
\hline $\begin{array}{l}\text { Psychiatric referral in year before treatment } \\
\text { episode (yes } v \text { no) }\end{array}$ & 1.80 (1.48 to 2.18$)$ \\
\hline \multicolumn{2}{|l|}{$\begin{array}{l}\text { Psychotropic therapy in } 60 \text { days before treatment } \\
\text { episode: }\end{array}$} \\
\hline Any psychotropics (yes $v$ no) & 2.22 (2.01 to 2.46) \\
\hline Antipsychotics (yes $v$ no) & $1.07(0.93$ to 1.22$)$ \\
\hline Mood stabilisers (yes $v$ no) & $0.88(0.73$ to 1.06$)$ \\
\hline Diagnosis of depression (yes $v$ no) & $1.42(1.05$ to 1.91$)$ \\
\hline \multicolumn{2}{|l|}{ Medical history: } \\
\hline Bipolar disorder (yes $v$ no) & 1.47 (1.05 to 2.07) \\
\hline Depression (yes $v$ no) & $1.09(0.74$ to 1.59$)$ \\
\hline Eating disorder (yes $v$ no) & 1.71 (1.41 to 2.06) \\
\hline Personality disorder (yes $v$ no) & 1.78 (1.49 to 2.12) \\
\hline Substance misuse (yes $v$ no) & 2.24 (1.96 to 2.57$)$ \\
\hline \multicolumn{2}{|l|}{$\begin{array}{l}\text { Psychiatric morbidity in year before treatment } \\
\text { episode: }\end{array}$} \\
\hline Any psychiatric morbidity (yes $v$ no) & $1.01(0.82$ to 1.24$)$ \\
\hline Anxiety (yes $v$ no) & 1.11 (1.00 to 1.23$)$ \\
\hline Depression (yes $v$ no) & $1.46(1.22$ to 1.74$)$ \\
\hline Mixed anxiety and depression (yes $v$ no) & $1.00(0.88$ to 1.11$)$ \\
\hline Substance misuse (yes $v$ no) & 1.62 (1.35 to 1.95) \\
\hline $\begin{array}{l}\text { Any health problem before or during treatment } \\
\text { episode (yes } v \text { no) }\end{array}$ & 0.72 (0.61 to 0.83 ) \\
\hline
\end{tabular}

*Measures relative risk of completed suicide adjusted for each analysis covariate after adjustment for all other variables in model, including treatment. †Unadjusted values.

for misclassification of this magnitude would move the point estimate for the risk of completed suicide for venlafaxine compared with citalopram from 1.70 to 1.39 , and for attempted suicide from 1.20 to 1.07 . We anticipated that data for defining referrals to mental health care and admission to hospital, as well as data on prescriptions, were appropriate and comprehensive. Psychiatric diagnoses, however, may be undiagnosed or misclassified to a noticeable extent. Most notably, severity of disease, a strong determinant of suicide risk, could only be measured indirectly. Furthermore, recognised risk factors for suicide, such as hopelessness, impulsivity, and abuse (child, domestic, or sexual) ${ }^{21-23}$ unemployment, poverty, social isolation, and suicidal 
Table 5 Unadjusted and adjusted hazard ratios $(95 \% \mathrm{Cl})$ for completed and attempted suicides for venlafaxine treatment compared with citalopram, fluoxetine and dothiepin treatment when time at risk included seven or 14 days at imputed end of prescription

\begin{tabular}{|c|c|c|c|c|}
\hline \multirow[b]{2}{*}{$\begin{array}{l}\text { Event and } \\
\text { antidepressants }\end{array}$} & \multicolumn{2}{|c|}{14 days } & \multicolumn{2}{|c|}{7 days } \\
\hline & $\begin{array}{c}\text { Unadjusted } \\
\text { hazard ratio } \\
(95 \% \mathrm{Cl})\end{array}$ & $\begin{array}{c}\text { Adjusted } \\
\text { hazard ratio } \\
(95 \% \mathrm{Cl})\end{array}$ & $\begin{array}{l}\text { Unadjusted } \\
\text { hazard ratio } \\
(95 \% \mathrm{Cl})\end{array}$ & $\begin{array}{c}\text { Adjusted } \\
\text { hazard ratio } \\
(95 \% \mathrm{Cl})\end{array}$ \\
\hline \multicolumn{5}{|c|}{ Completed suicide: } \\
\hline $\begin{array}{l}\text { Venlafaxine } v \\
\text { citalopram }\end{array}$ & $\begin{array}{c}2.44 \\
(1.12 \text { to } 5.31)\end{array}$ & $\begin{array}{c}1.70 \\
(0.76 \text { to } 3.80)\end{array}$ & $\begin{array}{c}2.56 \\
\text { (1.14 to } 5.77)\end{array}$ & $\begin{array}{c}1.87 \\
\text { (0.81 to } 4.29)\end{array}$ \\
\hline $\begin{array}{l}\text { Venlafaxine } v \\
\text { fluoxetine }\end{array}$ & $\begin{array}{c}2.85 \\
(1.37 \text { to } 5.94)\end{array}$ & $\begin{array}{c}1.63 \\
\text { (0.74 to } 3.59)\end{array}$ & $\begin{array}{c}3.19 \\
(1.46 \text { to } 7.00)\end{array}$ & $\begin{array}{c}1.87 \\
\text { (0.81 to } 4.32)\end{array}$ \\
\hline $\begin{array}{l}\text { Venlafaxine } v \\
\text { dothiepin }\end{array}$ & $\begin{array}{c}2.54 \\
\text { (1.07 to } 6.02)\end{array}$ & $\begin{array}{c}1.31 \\
\text { (0.53 to } 3.25)\end{array}$ & $\begin{array}{c}2.37 \\
(0.98 \text { to } 5.73)\end{array}$ & $\begin{array}{c}1.27 \\
\text { (0.51 to } 3.18)\end{array}$ \\
\hline \multicolumn{5}{|c|}{ Attempted suicide: } \\
\hline $\begin{array}{l}\text { Venlafaxine } v \\
\text { citalopram }\end{array}$ & $\begin{array}{c}1.49 \\
(1.34 \text { to } 1.66)\end{array}$ & $\begin{array}{c}1.20 \\
(1.07 \text { to } 1.34)\end{array}$ & $\begin{array}{c}1.52 \\
(1.36 \text { to } 1.69)\end{array}$ & $\begin{array}{c}1.23 \\
(1.10 \text { to } 1.37)\end{array}$ \\
\hline $\begin{array}{l}\text { Venlafaxine } v \\
\text { fluoxetine }\end{array}$ & $\begin{array}{c}1.68 \\
(1.52 \text { to } 1.86)\end{array}$ & $\begin{array}{c}1.28 \\
(1.15 \text { to } 1.42)\end{array}$ & $\begin{array}{c}1.68 \\
(1.52 \text { to } 1.87)\end{array}$ & $\begin{array}{c}1.28 \\
(1.14 \text { to } 1.43)\end{array}$ \\
\hline $\begin{array}{l}\text { Venlafaxine } v \\
\text { dothiepin }\end{array}$ & $\begin{array}{c}2.41 \\
\text { (2.11 to } 2.74)\end{array}$ & $\begin{array}{c}1.47 \\
(1.29 \text { to } 1.68)\end{array}$ & $\begin{array}{c}2.38 \\
\text { (2.08 to } 2.72 \text { ) }\end{array}$ & $\begin{array}{c}1.45 \\
\text { (1.27 to } 1.67)\end{array}$ \\
\hline
\end{tabular}

ideation, are not routinely recorded in the general practice research database and could not be accounted for in this analysis.

Adjustment for measured confounders substantially reduced the excess risk of suicide associated with venlafaxine. As the amount of residual confounding tends to reflect the overall confounding in the data, ${ }^{20}{ }^{24}$ adjustment for measured confounding was unlikely to fully compensate for a potential bias introduced by systematic channelling of more severely depressed patients towards venlafaxine treatment. We suspect that correction for this residual bias could result in further change of the effect estimates towards the null value.

\section{Study strengths and limitations}

The major strength of this study was the large study population and the completeness of longitudinal records for assessment of drug use and measurement of risk factors. We also confirmed many of the expected associations with risk factors, such as markers of depression severity, and suicide risk. As with any retrospective study using secondary data, however, this study had several limitations, including lack of direct measurement of disease severity and partial assessment of some variables such as major life events that are likely to be inconsistently recorded in the general practice research database. The potential for some exposure and outcome misclassification should also be considered. We imputed drug use and time at risk on the basis of fully comprehensive prescription records from the database. However, prescribing within the secondary care setting might have been missing, leading to potential underestimation of drug use in more severe patients under psychiatric care. To impute duration of prescriptions and time at risk we made assumptions; overall compliance with treatments was also assumed. We used a sensitivity analysis to evaluate whether reducing the duration of drug use after the imputed end of prescriptions from 14 to seven days affected the relative risk estimate. Shortening the definition of time at risk only marginally and inconsistently increased the relative risk estimates and did not lead to a substantial difference in study results.

One of the strengths of the general practice research database is the high quality of information on mortality, including cause of death. ${ }^{118}$ None the less, in secondary data cause of death is associated with some misclassification, all the more given the nature of this specific study outcome, since completed suicide is most often an unwitnessed event and loaded with social stigma. Although we identified completed suicide in accordance with procedures previously published and validated ${ }^{10}{ }^{11}$ potential misclassification and under-ascertainment cannot be ruled out. We would anticipate that misclassification of completed suicides is less likely among people with most severe depression-that is, patients taking venlafaxine-who can be expected to be more closely monitored. Attempted suicide represented a less clearly defined outcome and non-differential misclassification, which may bias the relative risk towards the null, could occur.

\section{Conclusions}

We found a higher risk of suicide associated with venlafaxine compared with citalopram, fluoxetine, and dothiepin, which could reflect a causal association. However, because venlafaxine was channelled towards patients with more severe and treatment resistant depression, adjustment for measured risk factors could have left residual confounding that could explain some or all of the excess risk associated with venlafaxine.

We thank William Irish and Ken Rothman for their contribution to the analysis, interpretation of the results, and preparation of the manuscript.

Contributors: AR, NR, PT, EA were responsible for the study design, data analysis, and interpretation, with contributions from DM and SW. AR and NR developed the study protocol. NR was responsible for the statistical analysis. AR, PT, and SW reviewed notes for the definition of completed and attempted suicides. AR wrote the paper, with contributions from all authors. $\mathrm{EA}$ is the guarantor.

Funding: This study was sponsored by Wyeth, which produces and markets venlafaxine. The contract between RTI Health Solutions and Wyeth specified that the authors at RTI Health Solutions had ultimate control over all aspects of the study, including control over publication. During the course of the study, however, any differences about the presentation or interpretation of findings that arose between the company author and external investigators were resolved through honest scientific debate. All authors had access to the statistical reports and tables supporting the publication.

Competing interests: All other authors have no personal financial interest in the drug studies. RTI Health Solutions has received research funding from several companies, including Lilly, GlaxoSmithKline, and Pfizer, who market antidepressants and potentially gain or lose financially from the results of the study.

Ethical approval: This study was approved by the institutional review board at RTI International and the General Practice Research Database Scientific and Ethical Advisory Group.

\section{What is already known on this topic}

The risk of suicide during treatment with commonly prescribed selective serotonin reuptake inhibitors and tricyclic antidepressants is similar

The risk with venlafaxine, however, has not been evaluated in population based studies

\section{What this study adds}

Venlafaxine users were more likely to commit or attempt suicide than patients using citalopram, fluoxetine, or dothiepin

Venlafaxine users had a higher burden of suicide risk factors at start of treatment; adjustment for measured confounders reduced the excess risk

Because residual confounding was possible, the increased risk of suicide associated with venlafaxine therapy should not be seen as causal 
1 Committee for the Safety of Medicine (CSM) expert working group on the safety of selective serotonin reuptake inhibitor antidepressants, 6 Dec 2004. www.mhra.gov.uk (accessed 15 Mar 2006).

2 FDA reviews data for antidepressant use in adults. FDA talk paper (1 Jul, 2005). www.fda.gov/bbs/topics/ANSWERS/2005/ANS01362.html (accessed 4 Apr 2005).

3 Whittington CJ, Kendall T, Fonagy P, Cottrell D, Cotgrove A, Boddington E. Selective serotonin reuptake inhibitors in childhood depression: systematic review of published versus unpublished data [see comment]. Lancet 2004;363:1341-5.

4 Hammad TA, Laughren T, Racoosin J. Suicidality in pediatric patients treated with antidepressant drugs. Arch Gen Psychiatry 2006;63:332-9.

5 Khan A, Khan S, Kolts R, Brown WA. Suicide rates in clinical trials of SSRIs, other antidepressants, and placebo: analysis of FDA reports. Am J Psychiatry 2003;160:790-2.

6 Storosum JG, van Zwieten BJ, van den Brink W, Gersons BPR, Broekmans AW. Suicide risk in placebo-controlled studies of major depression. Am J Psychiatry 2001;158:1271-5.

7 Gunnell D, Saperia J, Ashby D. Selective serotonin reuptake inhibitors (SSRIs) and suicide in adults: meta-analysis of drug company data from placebo controlled, randomised controlled trials submitted to the MHRA's safety review. BMJ 2005;330:385.

8 Jick H, Ulcicka M, Dean A. Comparison of frequencies of suicidal tendencies among patients receiving fluoxetine, lofepramine, miansetin, or trazodone. Pharmacotherapy 1992;12:451-4

9 Jick SS, Dean AD, Jick H. Antidepressants and suicide. BMJ 1995;310:215-8

10 Jick H, Kaye JA, Jick SS. Antidepressants and the risk of suicidal behaviors. JAMA 2004;292:338-43.

11 Martinez C, Rietbrock S, Wise L, Ashby D, Chick J, Moseley J, et al. Antidepressant treatment and the risk of fatal and non-fatal self harm in first episode depression: nested case-control study. BMJ 2005;330:389-93

12 Didham RC, McConnell DW, Blair HJ, Reith DM. Suicide and self-harm following prescription of SSRIs and other antidepressants: confounding by indication. $\mathrm{Br} \mathrm{J} \mathrm{Clin}$ Pharmacol 2006;60:519-25.

13 Juurlink DN, Mamdani MM, Kopp A, Redelmeier DA. The risk of suicide with selective serotonin reuptake inhibitors in the elderly. Am J Psychiatry 2006;163:813-21.

14 Stahl SM, Grady MM, Moret C, Briley M. SNRIs: their pharmacology, clinical efficacy, and tolerability in comparison with other classes of antidepressants. CNS Spectr 2005;10:732-47.

15 Rush AJ, Trivedi MH, Wisniewski SR, Stewart JW, Nierenberg AA, Thase ME, et al. Bupropion-SR, sertraline, or venlafaxine-XR after failure of SSRIs for depression. $N$ Engl J Med 2006;354:1231-42.

16 Mines D, Hill D, Yu H, Novelli L. Prevalence of risk factors for suicide in patients prescribed venlafaxine, fluoxetine, and citalopram. Pharmacoepidemiol Drug Saf 2005; 14:367-72.
17 Walley T, Mantgani A. The UK general practice research database. Lancet 1997;350:1097-9

18 Garcia Rodriguez LA, Perez Gutthann S. Use of the UK general practice research database for pharmacoepidemiology. Br J Clin Pharmacol 1998;45:419-25.

19 Egberts AC, Lenderink AW, de Koning FH, Leufkens HG. Channeling of three newly introduced antidepressants to patients not responding satisfactorily to previous treatment. J Clin Psychopharmacol 1997;17:149-55.

20 Savitz DA, Baron AE. Estimating and correcting for confounding misclassification. Am JEpidemiol 1989;129:1062-71.

21 De Hert M, McKenzie K, Peuskens J. Risk factors for suicide in young people suffering from schizophrenia: a long-term follow-up study. Schizophr Res 2001;47:127-34.

22 Plunkett A, O’Toole B, Swanston H, Oates RK, Shrimpton S, Parkinson P. Suicide risk following child sexual abuse. Ambul Pediatr 2001;1:262-6.

23 Simon TR, Anderson M, Thompson MP, Crosby A, Sacks IJ. Assault victimization and suicidal ideation or behavior within a national sample of US adults. Suicide Life Threat Behav 2002;32:42-50.

24 Rothman KJ, Wentworth III CE. Mortality of cystic fibrosis patients treated with tobramycin for inhalation. Epidemiology 2003;14:55-9.

(Accepted 7 November 2006)

doi 10.1136/bmj.39041.445104.BE

RTI Health Solutions, Manchester Science Park, Manchester M15 6SE

Annalisa Rubino director, epidemiology

Neil Roskell associate director, statistics

RTI Health Solutions, Research Triangle Park, NC, USA

Pat Tennis senior director, epidemiology

Global Safety Surveillance and Epidemiology, Wyeth Research, PA, USA

Daniel Mines senior director, epidemiology

Warwick Medical School, University of Warwick, Coventry

Scott Weich professor of psychiatry

Pharmacoepidemiology and Risk Management, RTI Health Solutions, Research Triangle Park, USA

Elizabeth Andrews vice president

Correspondence to: A Rubino arubino@rti.org 